\title{
O ADOLESCENTE E A CULTURA DO CORPO NA CONTEMPORANEIDADE*
}

\section{THE ADOLESCENT AND THE CULT OF THE BODY IN CONTEMPORARINESS}

\author{
Eliana Julia Garritano \\ Glória Sadala, \\ da Universidade Veiga de Almeida
}

\section{RESUMO}

Este artigo tem como objetivo apresentar uma análise do sujeito adolescente e do culto promovido ao corpo na contemporaneidade. A partir da relevância que o corpo do jovem assume como ideal na cultura contemporânea, buscamos correlacionar, à luz da psicanálise, as interferências do consumo excessivo e da saturação do mundo de imagens direcionados ao corpo como geradoras de uma possível inflação narcísica do sujeito adolescente. $\mathrm{O}$ apelo fortemente idealizado à imagem do corpo parece estar regulando as relações entre os jovens, de forma a qualificar, ordenar e excluir aqueles que não seguem o padrão vigente de perfeição e beleza. Assim, acreditamos que o adolescente aprisionado à teia narcísica gerada pela cultura do corpo tem sua construção subjetiva severamente prejudicada.

Palavras-chave: Adolescente. Corpo. Psicanálise. Contemporaneidade.

A palavra Adolescens é encontrada pela primeira vez nas comédias de Plauto, em torno de 193 d.C. (POLLO, 2003). Tem sua origem no vocábulo latino adolescere, que significa fazer-se homem, ou mulher, ou crescer na maturidade. (MUUSS, 1976)

O nascimento da adolescência como período etário, é uma decorrência do surgimento da moderna noção de família e de infância. Philippe Ariès (1981) descreve este surgimento a partir do século XVIII.

A partir do séc.XIX, surge o adolescente na cultura ocidental, sem que haja ritos de passagem definidos. $\mathrm{O}$ nascimento da adolescência, enquanto uma idade diferenciada ocorre concomitante com o individualismo, um dos valores básicos da nossa sociedade. Firma-se entre as duas guerras, juntamente com a ascensão da mídia e do consumismo, na segunda metade do século XX.

Embora o conceito sofra modificações em relação à idade e ao sexo, a maioria dos autores atribui-lhe o critério de passagem entre a infância e a vida adulta. É considerado por alguns autores um período transitório, onde rupturas e paradoxos exercem influências no comportamento; um tempo de mudanças que pode ser entendido como uma transição entrecortada por muita turbulência e pouca calmaria. Em algumas culturas, é um período marcado por ritos de passagem, variando sua duração de cultura para cultura.

É importante apresentar a diferença que se encontra em alguns autores entre puberdade e adolescência. A puberdade consiste de modificações de caráter orgânico e

\footnotetext{
* Artigo recebido em 02/03/2009 e aprovado em 15/05/2009
} 
fisiológico, podendo ser determinada como um período de desenvolvimento. O dispositivo biológico é disparado no cérebro, provocando crescimento, aumento de massa corporal e aquisição da função reprodutora. A adolescência é caracterizada por um tempo não cronológico, mas sim lógico, onde as mudanças corporais e a assunção de papéis sociais irão exigir um intenso trabalho de reelaboração psíquica. Um tempo ímpar na vida do sujeito, de mudanças geradoras de uma metamorfose afetiva, sexual e social, implicando conflito e angústia, inerentes ao vazio que emerge frente à necessidade de fazer escolhas.

Adolescência não é um conceito clássico em psicanálise. As descobertas de Freud relativas à primeira infância vão estabelecer com a adolescência uma relação casual e direta, interrompida pela latência, sendo o construto psicanalítico sobre a infância concebido a partir da análise de jovens adultos. Para a psicanálise, a sexualidade é bifásica. Os fenômenos da adolescência, embora manifestados com a chegada da puberdade, são edificados sobre os antecedentes da primeira infância.

Freud (1969g), em Três ensaios sobre a teoria da sexualidade, determina que o despertar da adolescência é laborioso, por resgatar as primeiras manifestações da sexualidade, pelas transformações corporais, pela explosão endócrina e por todos os lutos que o adolescente precisa viver. Esse despertar implica dois trabalhos básicos: o encontro com o real do sexo e o desligamento dos pais da infância.

Tomemos aqui uma passagem dos Três ensaios sobre a teoria da sexualidade.

Ao mesmo tempo em que as fantasias claramente incestuosas são superadas e repudiadas, consuma-se uma das mais significativas e, também, uma das mais dolorosas realizações psíquicas do período puberal: o desligamento da autoridade dos pais, um processo que sozinho, torna possível a oposição, tão importante para o progresso da civilização, entre a nova geração e a velha. (FREUD, 1969g, p.234).

Esta passagem não nos deixa dúvidas de que o árduo trabalho da adolescência implica um desligamento psíquico da autoridade dos pais, para que sejam elaboradas novas escolhas tanto sexuais como profissionais. Esse trabalho de desligamento é importante, não só para o adolescente em si mesmo, mas também para o caminhar da civilização.

Freud nomeia a adolescência de puberdade, marca responsável por múltiplas mudanças tanto físicas como psíquicas, influenciando diretamente o comportamento adolescente. A chegada da puberdade irá refletir na vida afetiva, nos interesses, na interação social e nas futuras escolhas.

A possibilidade orgânica da genitalização, na adolescência, coloca em questão o despertar das fantasias edípicas e o reordenamento da pulsão, metamorfoseando o corpo e o psiquismo. Tais transformações geram flutuações, onde o mais familiar dos objetos ou mesmo o próprio corpo perdem sua evidência, para ressurgirem como absolutamente estranhos. Este apagamento provoca no adolescente uma vacilação tanto narcísica quanto objetal.

Para que haja o desligamento dos pais da infância, é necessário que o adolescente vacile, aparecendo sua precariedade como falha no real. Para desligar-se, é necessário certo distanciamento, onde a aparente rebeldia pode muito mais estar a serviço do apelo aos pais para que manifestem de alguma forma sua autoridade na restrição de seu gozo. A questão do pai como função simbólica é suporte para o apelo adolescente em relação ao gozo que o 
invade. O pai, embora também barrado, é, por vezes, impotente quanto a responder às questões da adolescência, mas é suporte imprescindível por suas referências primárias.

Ao abandonar determinadas identificações imaginárias, o adolescente deverá projetar diante de si algo que substituirá o narcisismo perdido de sua infância, tornando-se a construção de ideais e valores éticos fundamental para a adolescência. A passagem edípica sedimenta o Ideal do eu, como instância principal que irá assumir o papel de orientador dos projetos de vida, escolhas e metas. Essa passagem é citada no artigo Sobre o narcisismo: uma introdução (1969f), onde Freud escreve: "o que ele projeta diante de si como sendo o seu ideal é o substituto do narcisismo perdido de sua infância na qual era seu ideal." (FREUD (1969f, p.111).

Assim, podemos inferir que é fundamental considerar a formação do Ideal do eu na adolescência, onde a construção de novos valores ocupa lugar de referência para a saída do narcisismo infantil. $\mathrm{O}$ adolescente fixado na cultura de seu próprio corpo tem a vida psíquica prejudicada, acarretando um empobrecimento em suas trocas relacionais e, segundo Freud, "onde não se forma tal ideal a tendência sexual aparece alterada na personalidade sob a forma de uma perversão." (FREUD (1969f, p.118).

Freud (1969g) em seus Três Ensaios, afirma que o comportamento sexual normal desenvolve-se a partir de inibições psíquicas que funcionam como barreiras. As exigências dos ideais sublimados e morais vão reorientar a vida pulsional, sendo que a realização de um ideal torna-se também fonte de prazer, promovendo o laço social e a inscrição no mundo profissional.

$\mathrm{O}$ enfraquecimento da autoridade paterna e a impossibilidade de encontrar substitutos na sociedade contemporânea geram não somente perturbações no adolescente, mas também conseqüências na própria sociedade, pois, segundo Lacan, o social também pode assumir a função do pai.

Não cremos que a adolescência seja caracterizada por uma crise, pois isso nos levaria a pensar em uma abordagem bastante reducionista. Os fenômenos da adolescência que se escondem atrás das ditas "crises adolescentes" apontam para questões edípicas revividas no período da adolescência.

A questão edípica intervém na determinação do tipo de escolha de objeto, nas identificações e na constituição do desejo, sendo tais questões estruturais de crucial importância na constituição do sujeito adolescente. O interdito, a ordem e a lei necessários à entrada na cultura, conferem ao Édipo uma estrutura, uma organização central do sujeito e estão intimamente articulados às questões da adolescência, à construção de ideais e ao acesso à vida em coletividade.

Acreditamos que a constituição do sujeito contemporâneo esteja mais determinada pela via da identificação imaginária, materializada pelo repertório midiático de imagens, do que por identificações operadas por instâncias simbólicas. Com a criação da estética jovem para todos, é possível afirmar a existência de um ideal cultural com o qual os adultos passam a se identificar. Constatamos em algumas famílias contemporâneas um movimento de abolição de diferenças. A partir das últimas décadas do século XX, a mídia passou a promover um movimento em direção ao apagamento de diferenças. Os pais deixavam de ser pais e passavam a ser colegas de seus filhos. Pais passam a freqüentar os mesmos espaços, a usar a mesma linguagem, as mesmas roupas e a ter os mesmos hábitos. Apagada a diferença de gerações, todos se tornam adolescentes. Embora o adolescente necessite 
separar-se de seus pais, condição preponderante para conquistar seu desejo, é exatamente na adolescência o tempo em que o sujeito necessita mais de seus pais como figuras primeiras de identificação e referência.

$\mathrm{O}$ afrouxamento da autoridade paterna gera angústia no adolescente pela falta de sustentação que promove, pois a presença dos pais junto aos filhos é o principal fundamento para que ele, o jovem, possa deles se separar. A cultura contemporânea oferece ao adolescente um espelho totalizante, uma imagem sem furo, negando a castração.

Freud, em $O$ mal estar na Civilização (1969a), aponta para três fontes de sofrimento humano: a natureza como um poder superior, a fragilidade de nossos corpos e a inadequação das regras necessárias aos relacionamentos humanos quer na família, quer no Estado, quer na sociedade. A vida em coletividade implica frustrações impostas, estando a redução das exigências pulsionais, a serviço dos ideais culturais.

A adolescência muito nos parece falar desse mal estar, que tem sua origem no abdicar dos desejos edípicos incestuosos e hostis, em prol do viver em coletividade e da busca de ideais.

Consideramos o complexo de castração, vivido no conflito edípico, a referência principal para as questões em relação ao adolescente. O complexo de castração é marcado pela falta e pelo preenchimento de um vazio através do falo. A função paterna, a interdição, e o não acesso irrestrito ao gozo instituem a ordem simbólica, onde o falo irá preencher o vazio e organizar as relações. Com o acesso à linguagem, o desejo passa a ser nomeado. A castração simbólica permite a interiorização da lei, onde a criança se constitui como sujeito.

Dessa forma, a metáfora paterna leva à instituição de algo que é da ordem do significante, internalizado como uma insígnia, Ideal do eu, e será guardado, retornando na adolescência.

Com a saída do Édipo, instala-se a latência, período de grande importância para a adolescência. A latência já descortina um desligar-se, pois busca um saber que não está mais nos pais. Embora para Freud, "o encontro de um objeto é, na realidade, um reencontro dele" (1969g, p.229), esse novo encontro é redimensionado pelo simbólico.A chegada da adolescência indica o final da latência, com o despertar da sexualidade adormecida.

A adolescência é um momento determinante na estruturação psíquica, um tempo mestre que possui uma lógica própria. Envolve um extenso trabalho de escolhas, motivado pelo desligamento dos pais da infância, pelo encontro com o real do sexo e pela elaboração da falta no Outro.

O corpo, como imigrante em sua própria casa, encontra-se no centro da maior parte dos conflitos do adolescente. As transformações da puberdade em pouco mais de três anos transformam o corpo, não somente pelo acesso à genitalidade, mas também pelo acréscimo de massa corporal em altura e peso. O adolescente não está frente a uma versão aumentada do corpo infantil, mas, diante de um corpo imaginário e desproporcional, que não mais corresponde à sua antiga imagem.

A irrupção da sexualidade, interrompida pela latência, recoloca a questão da imagem até então construída. O trabalho de luto para aquisição de novos objetos põe em jogo as moções pulsionais, levando o adolescente à utilização do corpo como suporte do discurso do Outro. A imagem corporal é, então, ultrapassada pelas intensas transformações da puberdade e, dessa forma, a adolescência vai reeditar algo do narcisismo e do estádio do espelho. A imagem ideal, até então sustentada pelos pais da infância, torna-se altamente 
ameaçada frente ao olhar do Outro. O distanciamento do universo infantil requer a elaboração de um luto, para que um novo estatuto corporal seja construído. A retração da libido narcisista torna-se então necessária para que o adolescente não naufrague. Saindo da posição de amado incondicionalmente, o adolescente tem à sua frente a difícil tarefa de amar, mas amar de uma nova maneira, quase fantasmática, ou seja, amar o desconhecido. O corpo, na travessia da imagem, passa a ocupar um lugar de investimento onde o eu, sem dúvida, vai vacilar.

Identificações anteriores são substituídas pela identificação com objetos abstratos, tais como valores, atitudes, ética. Os anseios do Ideal do eu buscam diferentes formas de elaboração por um processo inter-relacional com a realidade. $O$ direcionamento da satisfação pulsional, por meio de objetos substitutos é, segundo Freud, o caminho para a pulsão desviar-se da perversão. Dessa forma, podemos inferir que a formação do Ideal do eu promove o refluir da libido narcísica na busca de novos objetos, necessários à adolescência.

$\mathrm{Na}$ adolescência, são consolidados os sentimentos de respeito, fidelidade, valores éticos e morais. Edificam-se aspirações pessoais e sociais, com a busca de novos pares e novos ideais. As relações sociais são estabelecidas pelo trocar, pelo compartilhar com o grupo social determinada cultura. Nessa busca, são vários os lutos que o adolescente precisa viver, dentre os quais o luto pelo próprio corpo que se transforma e lhe é desconhecido e o luto pelos pais da infância. A apropriação do novo status é imanente aos lutos que precisa viver.

A construção de ideais, a sublimação e a busca do Outro são fatores preponderantes para o fortalecimento do eu. Ideais, valores éticos e morais ocupam lugares necessários ao refluir da libido narcísica. A busca da perfeição narcísica, tão comum na adolescência, demonstra a dificuldade de transpor o eixo eu ideal/Ideal do eu. A identificação com a imagem narcísica, reforçada pela sociedade contemporânea, mantém o adolescente em uma falsa imagem de perfeição, e a castração simbólica não efetuada perpetua o falo no próprio corpo.

A escolha de objetos na adolescência encontra-se intimamente relacionada ao processo de novas identificações. Assim, na busca de seus pares, temos as formações das "tribos", onde a imagem é reafirmada. Na fidelidade aos pares, o jovem busca o entendimento de si mesmo, formulando valores no seio de seu grupo. A fidelidade é a base na qual o adolescente busca verdades, na afirmação de seus companheiros.

A identificação simbólica é de grande importância para a compreensão das questões na adolescência, pois aponta para o Outro, uma posição externa, como possibilidade de articulação do universo de identificações.

As questões referentes ao narcisismo, no sujeito adolescente, vinculam-se às oscilações do Ideal do eu, que ao mesmo, tempo em que confere sustentação, sofre imposições advindas do contexto social. O conflito adolescente liga-se, em parte à incapacidade de, a partir da identificação fundante, gerar respostas às solicitações sociais. A necessidade de remanejar antigas identificações gera respostas confusas e antagônicas.

A adolescência pode ser considerada como paradigma dos impasses do sujeito frente à confrontação com a incompletude. A sustentação no Outro, até então suposta pela criança, se desvanece. Ao constatar a inconsistência do Outro, ou seja, que o Outro também é falho, o adolescente, inicia, então, longo e árduo caminho de elaboração. $\mathrm{O}$ apelo ao 
Outro vai esbarrar na falta, falta que propicia o desligamento da autoridade paterna. A constatação do vazio torna-se o principal vetor para o seu desligamento. Consideramos a adolescência um ato de coragem, visto que viver a adolescência implica uma travessia árdua para novas realizações, até então desconhecidas.

Os questionamentos adolescentes direcionam-se não só ao âmbito familiar mas também a qualquer ordem institucional estabelecida (escola, sociedade, religião). As repetidas tentativas de separação dos objetos primários de amor, os pais, levam à busca de amizades íntimas e idealizadas, estabelecendo-se laços fraternos. A fraternidade e a amizade tornam-se a principal forma de vinculação, independente do sexo. A escolha de objetos na adolescência pode ser caracterizada, por um lado, pelo abandono e, por outro, pelo reencontro, sendo marcada por profunda incongruência.

Pela oscilação e ambivalência, os afetos adolescentes são intensos, porém passageiros. São amizades profundas, exclusivas ou amores apaixonados. Os objetos na adolescência, raramente são definitivos, operando, na realidade, como fixações identificatórias do modelo narcísico, como forma de reeditar o passado no presente, articulando uma passagem necessária ao universo social.

O grupo oferece uma ancoragem, promovendo a adaptação a determinadas regras num consenso de aceitação mútua. Os impulsos de rebelião, oposição, resistência, a prática de excessos e a experimentação são condutas comuns em grupos jovens. As atuações em grupo, em nossa sociedade ocidental, podem representar ritos de passagem muito necessários na adolescência. $\mathrm{O}$ culto ao corpo pode ser considerado como forma simbólica de inscrição em uma cultura tão narcísica quanto violenta. São comuns os grupos adolescentes voltados para a prática de lutas, artes marciais, onde o corpo ultra "malhado" presentifica a chamada geração pit bull.

$\mathrm{O}$ adolescente. na relação com o grupo, cria o lugar dos ritos de passagem. A cultura do corpo, tatuagens, piercings, a moda irreverente e bizarra são marcas de inscrição e diferenciação. O grupo, movido pelas relações entre sujeito objeto, é ponto de referência e iniciação, estabelecendo normas, costumes e códigos. É em torno do significante como certo número de palavras, jargão ou gírias que o grupo existe e se organiza em uma linguagem intercambiável.

Freud (1969b), em seu artigo Psicologia de Grupo e análise do ego, compara o estado de hipnose e a formação de grupo, estabelecendo semelhanças. Este fenômeno é comum nas identificações grupais na adolescência. As aquisições individuais desaparecem temporariamente no grupo. O adolescente abandona seu ideal, substituindo-o pelo ideal do grupo, sendo este, muitas vezes, corporificado na figura de um líder messiânico, ocorrendo uma super identificação em massa, onde as regras são imperiosas. As atuações grupais, bem como as de seus integrantes, representam uma oposição às figuras parentais, apontando para enlaces fora do seio familiar. A dependência dos pais transfere-se ao grupo, constituindo a transição necessária para o mundo externo.

Essas condutas podem operar como mecanismo defensivo frente à culpa inconsciente e ao luto não elaborado pela infância. A emergência de crises religiosas também é comum nas manifestações grupais. O adolescente vacila entre momentos de fanatismo místico ou ateísmo absoluto. Determinadas seitas religiosas cooptam adolescentes como seguidores de um líder salvador. São freqüentes os discursos sobre diferentes seitas, crenças, religiões, devido à necessidade de identificação com imagens 
idealizadas e líderes religiosos. Como seu oposto, encontramos atitudes materialistas, niilistas, que desembocam num total ateísmo, como forma compensatória e defensiva.

Através de múltiplas experiências, o adolescente busca uma nova imagem para si. Todas as formas de aproximação e afastamento são experimentos dos quais o adolescente lança mão, como objetos investidos pulsionalmente.

$\mathrm{O}$ novo, ao mesmo tempo temido e desejado, imanta o olhar do adolescente. $\mathrm{Na}$ construção de uma nova imagem ressitua objetos infantis, atualizados pela genitalidade. Neste caminho de transição, a retração da libido narcísica pode ser compreendida como forma de erigir um novo estatuto, que representa não só a sexualidade, mas também a possibilidade de inserção no social.

$\mathrm{Na}$ adolescência, a sexualidade desperta e se transforma. Este despertar, nem sempre tranqüilo, necessita de novos engajamentos. Os jovens estabelecem códigos de comportamento que lhes permitam uma sustentação simbólica.

A experiência do olhar se transforma num complexo interjogo onde o desejo está implícito. O olhar do outro significativo embute todo um conjunto de mensagens, valores, apreciações e discriminação que erotizam o corpo, satisfazendo o desejo narcisista na essência de sentir-se único e desejado, através de um olhar que assim o ateste, pois outrora o olhar organizador da mãe tornou-se repleto de significantes primordiais com o qual a criança se identificou.

$\mathrm{Na}$ adolescência, como réplica do estádio do espelho, o sujeito vai se reapropriar da imagem corporal sob o olhar do Outro. A sexualidade interrompida pela latência tem, agora, possibilidades concretas de efetivação e o corpo erógeno passa a ter status de primeira grandeza. A imagem corporal é afetada de múltiplas formas, tanto em relação aos seus atributos como em relação ao seu funcionamento. A semelhança com o corpo adulto marca a importância do sexo oposto.

O corpo que ao mesmo tempo torna-se desejante e desejado, sujeito e objeto, reafirma seu estatuto de valor simbólico. Navegando entre o semelhante e o diferente, o familiar e o estranho, o adolescente busca ancoragem na figura ideal do Outro. É sob este olhar, que seu próprio olhar não mais se reconhece. A estruturação da imagem corporal é, então, posta à prova para além do olhar dos pais que até então a sustentaram.

Vivemos predominantemente em uma cultura narcísica, onde a beleza e a perfeição corporal são instauradas, juntamente a uma precariedade simbólica que atinge a todos. Se o adolescente vai requisitar o simbólico como em nenhum outro momento, conseqüentemente será mais atingido por esta precariedade. Ao lhe faltar o simbólico, é no imaginário que vai buscar sua sustentação, tornando-se o ponto nevrálgico de uma cultura predominantemente narcísica, por sua necessidade de retomada da construção de uma imagem corporal e de um simbólico que lhe permita tal reconstrução.

Sendo a adolescência um tempo de retomada do narcisismo e do estádio do espelho, em função do abalo sofrido pela perda da imagem corporal infantil, o adolescente necessita readquirir o júbilo narcísico que lhe dê uma nova unidade, em seu reencontro com a sexualidade. Embora a retomada do narcisismo e do estádio do espelho não seja exclusiva da adolescência, é o sujeito adolescente aquele que ocupa, de forma privilegiada, este lugar de passagem.

O corpo jovem passou a funcionar, na cultura contemporânea, como indexador econômico, regulador de uma multiplicidade de investimentos. A exaltação corporal, 
através da eternização da juventude, conclama a beleza como aparência de felicidade, sucesso e imortalidade. Assim, é produzida a imagem do belo corpo que traduz o anseio atual. O corpo cortado, recortado e aspirado nas intervenções cirúrgicas, malhado e suado nas academias, adornado pelo consumo, é o corpo ideal, transformado em signo cultural e fonte de capital.

O interesse midiático pelas questões que envolvem o corpo é expresso na quantidade de reportagens veiculadas abordando saúde, estética e rejuvenescimento. Saindo do espaço privado, o corpo, pela imagem, toma a cena social, ocupando grande fatia do espaço público. As demandas sociais relacionadas ao hedonismo fortalecem os apelos ao corpo, como um objeto de investimento e, portanto de valor econômico. Na ressacralização do corpo como objeto vinculado ao suporte econômico e ao controle social, o adolescente tem representado uma grande fatia deste mercado de consumo. Temos, então, uma ética de consumo que centra na cultura do corpo e no individualismo a salvação econômica.

O culto à imagem gera um turvamento do campo simbólico na construção subjetiva do adolescente. As estratégias narcisistas de sobrevivência apresentam-se como libertadoras das condições repressoras do passado, originando uma verdadeira "revolução cultural", revolução que, com novas roupagens, repete os aspectos de aprisionamento, frutos de sua própria crítica. Na busca de um sentido para a vida, o sujeito adolescente, constituído na cultura narcísica, torna-se ferozmente competitivo em função de sua necessidade de reconhecimento e aprovação. Em seu imediatismo, nega o passado, não se vinculando ao futuro.

Chegamos ao século XXI com soluções muito próximas, talvez, das fórmulas mágicas de alquimistas da antiguidade, na busca da eterna juventude. Estes múltiplos recursos, nada mais são do que uma busca frente ao desencantamento do mundo, tendo todos um denominador comum na afirmação narcísica do eu, fazendo crer na sua soberania e completude. A negação da castração gera uma desilusão frente ao outro e, sobretudo, uma incapacidade de aceitação da alteridade.

Roudinesco (2006) usa a expressão "culto a si”, para designar a cultura narcísica. Segundo a autora, a figura de Narciso vem substituir um Édipo soberano e ressentido. Com o declínio da autoridade das figuras parentais, é o mito de Narciso que passa a caracterizar uma sociedade sem interdito, sob o fascínio ilimitado do Eu. Se o Édipo é o herói emblemático que traduziu o poder patriarcal, condenando-se para que outras gerações pudessem advir, Narciso põe fim à vida por não aceitar perder o que os outros depois dele pudessem receber.

Roudinesco, a este respeito, afirma:

[...] pelo culto do narcisismo, a obsessão de si mesmo é sempre portadora de uma rejeição ao outro, transformada em ódio de si e, portanto, em ódio pela presença do outro em si, [...] Narciso é o drama de um Eu que se subtrai progressivamente a qualquer encontro com a verdade ao substituir o peso das tradições pelo deleite a si. (ROUDINESCO, 2006, p.52)

Dessa forma, no mundo unificado pela economia de mercado e centrado no individualismo, crescem as ilusões narcísicas em relação a um Eu soberano e individualista, que empobrece os vínculos sociais. A cultura do narcisismo promove a dialética inconsciente do estádio do espelho: o júbilo e a agressividade, pois para que o eu triunfe em 
seu gozo soberano, o outro não pode existir. "O culto de si é transformado em ódio de si e em desejo de destruição do outro." (ROUDINESCO, 2006, p.53).

Na verdade, uma cultura narcísica, com a ilusão de plenitude, mostra a sua outra face de profundo desamparo. Frente às incertezas do devir, a falsa liberdade nada mais traduz do que o rígido engessamento especular. A idéia de que há liberdade para tudo experimentar, leva o jovem a entrar em um mundo selvagem e competitivo. Esse estado de prontidão não abre espaço para o afeto, privando o sujeito do encontro com seu desejo.

A cultura do corpo promove uma sociedade sem interdito, sob o fascínio ilimitado do Eu. Faz crescer as ilusões narcísicas, empobrecendo os vínculos sociais, acirrando o individualismo e a competitividade, gerando a submissão limitadora da subjetividade e a punição para os que fogem ao padrão estabelecido, levando ao consumo de múltiplos objetos geradores de angústia, pois em nenhum deles pode ser encontrada a pretensa plenitude.

Ao alimentar a economia pelo consumismo, a cultura do corpo descobre o seu mais precioso veio: o aprisionamento do desejo do sujeito adolescente e de seu corpo. O poder da imagem ideal, ao delimitar um campo de referência narcísica torna-se um poder regulador em relação aos corpos. O que foge ao padrão ideal é considerado anormal, desviante, ou, mais sutilmente, chamado de alternativo. O sujeito contemporâneo passa a se constituir no interior de uma ditadura estética que, atravessando os tempos, apresenta-se hoje mais poderosa do que em qualquer época. Na cultura do corpo, o sujeito abandona referências corporais estáveis e passa a identificar-se com uma mutação constante e performática.

Sabemos que qualquer construção sempre foi determinada e circunscrita a sua própria cultura; dessa forma, o corpo ideal não estaria fora desta afirmação. Se na Idade Média os leprosos e as "bruxas" eram segregados e condenados à fogueira, na Idade Moderna, a ciência vai aprisionar os corpos loucos e doentes. Embora o mundo contemporâneo tenha "derrubado muros", foram criados outros, mais virtuais, midiáticos e não tão concretos. Entre a peste, o louco e o diferente pouco foi modificado em relação à busca da perfeição narcísica.

Segundo a psicanálise, qualquer referência ao sujeito é atravessada pela singularidade, em função do descentramento operado pelo desejo inconsciente e, em se tratando do sujeito adolescente, não seria diferente. Portanto, incorrer em sua generalização levará, possivelmente, a conclusões apressadas e enganosas. Embora saibamos que há tantas adolescências quanto adolescentes, podemos encontrar alguns significantes que se repetem em seu discurso. Um dos mais relevantes é o próprio corpo que se transforma.

Freud assinalava que a chegada da puberdade trazia consigo os investimentos objetais de épocas precoces, que eram, então, reanimados. A corrente terna da infância deveria então, convergir para a corrente sensual, sendo este encontro um dos trabalhos da adolescência. O sujeito adolescente é obrigado a se confrontar não só com as mudanças corporais relativas à puberdade, mas, também, com a pulsão que desperta.

Assim, o adolescente certamente caminha, com tropeços, tentando manter-se em um espaço entre dois mundos: um mundo que conhece e não quer mais, e um mundo que quer, mas não conhece. A corrente terna da relação de amor aos pais torna-se mesclada pela sensual, o que o obriga a desinvestir dos objetos parentais. Neste desinvestimento dos objetos edípicos, a libido retorna ao eu. Ao perder o valor da imagem corporal no 
narcisismo dos pais, o adolescente passa a investir em seu narcisismo tomando seu próprio corpo como principal objeto de amor. Nesta economia, necessária ao desligamento, passa a opor-se radicalmente à imagem referenciada na infância. Intensificam-se as questões em relação ao corpo em função das metamorfoses que a adolescência experimenta e tais mudanças fazem com que o sujeito adolescente retorne de certa forma ao narcisismo. Podemos afirmar que a adolescência reedita algo do narcisismo, e algo do estádio do espelho. Frente à perda da imagem corporal infantil e da criança ideal de outrora, o adolescente necessita readquirir o júbilo que lhe permita uma nova unidade, para que possa ressituar-se como sujeito da linguagem. É deste lugar que poderá reordenar suas vivências tanto reais como imaginárias. Pela ruptura com o vínculo infantil e transformação da imagem corporal, a adolescência torna-se um momento crucial em relação às referências simbólicas da cultura na qual está inserido.

Lacan nos diz que o sujeito sai do Édipo como detentor de títulos de propriedade no bolso. Estes títulos são guardados na latência como uma reserva, para serem usados com a chegada da adolescência. É, então, na adolescência que o sujeito irá "investir" seus títulos através da busca de seus ideais. Dessa forma, o Ideal do eu torna-se uma instância de extrema importância para o adolescente, posto que transmitido na infância, transforma-se na adolescência em metas ideais.

A cultura do corpo encontra-se altamente impregnada de ideais narcísicos não sublimados, onde o corpo jovem é tomado como paradigma ideal. Dessa forma, podemos considerar que a cultura na qual o sujeito adolescente irá consolidar seus ideais está marcada pelo hedonismo e pelo culto ao corpo.

$\mathrm{O}$ adolescente, ao resgatar seus "títulos", encontra em sua cultura suportes que o mantêm cativo, não conseguindo ir muito além do espelho. $\mathrm{O}$ jovem passa da submissão passiva do gozo, da criança-objeto do narcisismo dos pais para ser objeto de gozo de uma cultura narcísica.

No seminário livro 17, O avesso da Psicanálise, Lacan (1992) nos fala de objetos produzidos para causar o desejo, nomeando esses objetos de latusas. A cultura do corpo, que faz do adolescente o seu ideal, não cessa de produzir latusas, capturando o desejo do adolescente. É comum em nossos dias o uso da imagem do adolescente na propaganda. À mídia é conveniente e lucrativo usar o corpo jovem para vender seus produtos e idéias. A imagem do adolescente é utilizada para diversos fins lucrativos, pois com ela vende-se a moda, o saber, o lazer chegando ao extremo mais perverso da exploração sexual.

Se atribuirmos ao consumo o estatuto de parceria na construção subjetiva da adolescência, podemos então situá-lo na dimensão do gozo. A busca de "objetos latusas", que perpetuam a juventude, nega ao adolescente a castração necessária à instauração da lei. A cultura do corpo veicula a promessa de que nela poderá ser encontrada a completude, abolindo a falta que impulsiona o desejo.

O texto lacaniano de 1960, Subversão do sujeito e a dialética do desejo no inconsciente freudiano, (LACAN, 1998b) nos diz que é preciso que o gozo seja recusado para que possa ser atingido, na escala invertida da lei do desejo, pois só atravessado pela castração, o sujeito pode implicar-se em seu próprio desejo. Com tantas latusas, torna-se muito difícil a saída da adolescência visto que, tudo o que é bom, interessante e grandioso está circunscrito a esse tempo, transformando a maturidade num fardo a ser carregado e, 
portanto, postergado. O corpo jovem tomado como idealização máxima faz com que o adolescente, muitas vezes, ofereça-se ao gozo mortífero da pulsão de morte.

Considerando a adolescência um tempo de construção de ideais, para que tal construção aconteça é necessário um lugar cultural que ofereça possibilidades simbólicas de sublimação, onde a libido vai buscar novos objetos. Perguntamos então: que objetos nossa cultura oferece?

Uma cultura onde o corpo é tomado como principal objeto faz com que o adolescente continue aprisionado à teia do imaginário e às forças do recalque, não oferecendo as condições necessárias para que ideais sublimados possam ser atingidos. Nesse sentido, alguns adolescentes continuam alienados, não mais como objeto de gozo do narcisismo dos pais, mas como objeto de gozo de uma cultura narcísica que toma seus corpos como o próprio ideal. Dessa forma, a cultura contemporânea, no que diz respeito ao centramento no corpo jovem, toma-o como ideal de salvação na tentativa de escapar de seu próprio vazio e desamparo.

No consumo do corpo adolescente opera-se um consumo do próprio sujeito, com a devastação do campo de seu desejo. A questão que aqui se coloca é saber de que lugar simbólico o sujeito adolescente vai adquirir consistência imaginária, ou melhor dizendo, que lugar a cultura oferece como sustentação necessária para que a adolescência não naufrague?

A partir de uma perspectiva que articula o real e o imaginário ao simbólico, podemos asseverar que o corpo conjuga não só a imagem, mas também o significante. A partir da definição dos registros lacanianos do imaginário e do real, o imaginário é o sentido, e o real, como seu avesso, é o não sentido ou a ausência de sentido. É o simbólico como sendo da ordem do duplo sentido, aquele que marca o campo da linguagem pela incidência da lógica do significante, lugar da constituição do sujeito.

Para Lacan (1999), o desejo, ao cruzar o significante encontra o Outro como sede do código, produzindo a refração do desejo pelo significante. A partir da entrada no código da cultura, no encontro com o Outro, o sujeito já é submetido à dialética do desejo. Assim, qualquer satisfação possível do desejo vai depender do sistema significante articulado na fala do sujeito. Lacan destaca o significante $T u$ como a fala fundadora da história do sujeito. O Tu é o significante do apelo ao Outro. É aquele que invocamos como marca da construção subjetiva. Desta forma toda a satisfação da demanda, na medida em que depende do Outro, é autenticada pelo "Tu és". Mas a respeito de que o Outro faz apelo ao jovem? Tu és adolescente, és belo e teu corpo é promessa de eterna felicidade! Transformase, assim, o corpo adolescente no mais belo ideal a ser seguido e consumido, tomando-o como objeto de poder regulador.

De certa forma, Freud (1969f) em seu texto Sobre o narcisismo: uma introdução já preconizava este fenômeno, quando afirmava que o amor dos pais tão tocante e infantil, apesar de sua metamorfose em amor objetal, no fundo era o amor por si mesmo renascido. No narcisismo dos pais eram atualizadas suas próprias demandas de apagamento das leis da natureza, negando o envelhecimento, a doença e a morte. A afirmação freudiana nos permite entender como cada sociedade vai produzir sua adolescência, de acordo com cada época. Seria ingênuo pensar que em algum tempo o fenômeno da adolescência não tenha existido. As mudanças corporais e as exigências pulsionais sempre afetaram a subjetividade com suas especificidades, em relação à fase púbere. Mas, em outras épocas, os rituais de 
ordem simbólica marcavam o tempo da puberdade, tendo a função de sustentação para a apropriação do ser adulto. Embora o corpo também fosse objeto nos rituais de passagem, ele não era explorado em função do consumo e do capital. O corpo adolescente era tomado como o lugar de inscrição de novas marcas, insígnias de pertencimento, que delimitavam a morte da infância e o nascimento do adulto. Os rituais eram facilitadores desta passagem, e visavam à perpetuação da tradição e à ancestralidade. Na atualidade, a cultura contemporânea, ao negar a tradição e apostar no efêmero, traz as marcas do individualismo. $\mathrm{O}$ sujeito adolescente encontra-se mergulhado em um tempo desprovido de valores fixos, sendo obrigado a buscar valores em uma sociedade de múltiplas possibilidades, rápidas transformações e ameaças sucessivas, o que não lhe confere um conjunto ordenado onde possa fixar-se.

Freud (1969g) afirmava ser a puberdade um dos principais momentos de recrudescimento pulsional, quando a exigência da pulsão faz apelo a uma inscrição simbólica a partir do campo do Outro. Nos dias atuais, acelera-se a precariedade da maioria dos modelos nos quais o sujeito adolescente possa encontrar suporte. Essa precariedade aponta para uma redução no horizonte dos ideais, horizonte imprescindível para que a adolescência exista. Os pontos de suporte dos significantes que sustentam a adolescência contemporânea estão cada vez mais reduzidos ao narcisismo e ao hedonismo

$\mathrm{O}$ adolescente precisa encontrar na cultura em que vive figuras possíveis que possam confirmar seus ideais. Embora essas figuras ainda existam, parecem carecer de prestígio. Com o declínio das figuras da autoridade, começa a delinear-se um sujeito que, pelo empobrecimento de uma hetero-referência, define-se pelas lentes do individualismo e do narcisismo.

O tempo da adolescência não se define por uma temporalidade universal, mas sim lógica. Seu tempo implica luto e renascimento. Luto pela criança que naufragou ao Édipo, e que necessita afastar-se do suporte narcísico do eu ideal para trilhar um caminho com suas insígnias, referências herdadas ao final do complexo de Édipo que lhe permitam erigir o Ideal do eu.

O trabalho de luto realizado na adolescência necessita, como em nenhum outro momento, do suporte da cultura, pois libertar-se da autoridade dos pais, de modo algum implica abolir as referências simbólicas do significante paterno que constitui o sujeito em sua relação com a linguagem, marcando de forma singular o seu desejo. É justamente o traço transmitido na identificação com o pai, o Ideal do Eu, aquele que vai garantir o luto, dando suporte a novos investimentos objetais. É esta marca que permite ao adolescente retirar-se da alienação de seu próprio corpo, abandonando o lugar cativo de objeto de gozo do Outro, para lançar-se no caminho singular de seu desejo. O trabalho de luto ao qual Freud se refere nada mais é do que o abandono do lugar que o sujeito ocupava para o Outro, na ilusão de sustentação narcísica. Mas o luto também é instaurador de uma nova posição subjetiva e nova busca de objetos que permitam à pulsão circular.

Viver a adolescência é elaborar a falta e o vazio do Outro, e esta elaboração só se torna possível através da concordância com referências culturais simbólicas estáveis, fora do próprio corpo. Para tal se faz necessário considerar a sublimação como um dos caminhos fundamentais na construção de ideais. Para a psicanálise, o homem é o artesão de seus suportes e o que é a adolescência senão um período de construção artesanal? Freud (1969h) em um dos significados que conferiu ao conceito de sublimação, descreve seu 
sentido como sinônimo de verbalização, considerando-o uma forma sublime de contribuição cultural por permitir o desvio para objetos não sexuais. A palavra, como objeto sublimado, oferece à pulsão novas formas de satisfação. Nesse sentido, cabe a todos aqueles que ocupam o lugar de instância simbólica oferecer ao adolescente o campo fértil da palavra como ato criador.

É também com seu corpo que o adolescente vai buscar novas formas de inscrição, articulando toda a experiência corporal, com a marca de sua cultura. Tomar o corpo como um registro cultural é dotá-lo de registros que permitam afirmar a sua singularidade e diferença e, ao mesmo tempo, permitir o reconhecimento de laços com o coletivo. É nesta articulação entre a singularidade e a alteridade, no reconhecimento da diferença que encontramos uma dimensão ética para a experiência corporal do sujeito adolescente. Se a adolescência oscila entre o narcisismo e a alteridade, é nessa oscilação estrutural que o Outro deverá oferecer novas possibilidades de inscrição pulsional para que o sujeito adolescente possa abandonar a utilização voraz e predatória de seu próprio corpo operada pela pulsão de morte.

O defrontamento com o engodo da promessa narcísica é o que permitirá ao adolescente autorizar-se na busca de seu desejo, mas, para tal busca, é necessária a constatação da falta e, conseqüentemente da incompletude.

Acreditamos que, mesmo em um tempo onde a cultura do corpo aponta para a unificação que amordaça o sujeito adolescente, este possa agir e transformar o lugar que lhe oferecem, através do uso fértil da palavra como um ato de criação, na busca de novos horizontes culturais.

\section{ABSTRACT}

This article sets out to present an analysis of the adolescent subject and the encouragement of the cult of the body in the modern times. Out of the importance that the young person's body assumes as ideal in contemporary culture, we aim at correlating, in the light of psychoanalysis, the interferences of excessive consumption and the saturation of the world of images directed towards the body as sources of possible narcissistic inflation of the adolescent subject. The highly-idealized appeal of the image of the body would seem to be controlling relationships between young people, by qualifying, ordering and excluding those who do not follow the prevailing standards of perfection and beauty. Therefore, we believe that the adolescent's subjective construction, caught up in the narcissistic net created by the cult of the body, is seriously affected.

Key-words: Adolescent. Body. Psychoanalysis. Modernity

\section{REFERÊNCIAS}

ALBERTI, S. Esse sujeito Adolescente. Rio de Janeiro: Rios Ambiciosos, 1999. O adolescente e o Outro. Rio de Janeiro: Jorge Zahar, 2004. 
ARIÈS, P. História Social da Criança e da Família. 2.ed. Rio de Janeiro: Livros Técnicos e Científicos, 1981.

COSTA, A. Tatuagens e marcas corporais: atualizações do sagrado. São Paulo: Casa do Psicólogo, 2003.

FREUD, S. O Mal-estar na civilização [1930]. In: Obras Psicológicas Completas de Sigmund Freud. Rio de Janeiro: Imago, v. 21, 1969a.

. A dissolução do Complexo de Édipo [1924]. In: Obras Psicológicas Completas de Sigmund Freud. Rio de Janeiro: Imago, v.19, 1969 b.

Psicologia de grupo e a análise do ego [1921]. In: Obras Psicológicas Completas de Sigmund Freud. Rio de Janeiro: Imago, v. 18, 1969c.

Luto e melancolia [1915]. In: Obras Psicológicas Completas de Sigmund Freud. Rio de Janeiro: Imago, v.14, 1969d.

Os instintos e suas vicissitudes [1915]. In: Obras Psicológicas Completas de Sigmund Freud. Rio de Janeiro: Imago, v.14, 1969e

. Sobre o narcisismo: uma Introdução [1914]. In: Obras Psicológicas Completas de Sigmund Freud. Rio de Janeiro: Imago, v. 14, $1969 f$.

Três ensaios sobre a teoria da sexualidade [1905]. In: Obras Psicológicas Completas de Sigmund Freud. Rio de Janeiro: Imago, v. 7, 1969g.

Fragmento da análise de um caso de histeria (1901/05) In: Obras Psicológicas Completas de Sigmund Freud. Rio de Janeiro: Imago, v. 7, 1969h.

JORGE, M.A.C. Fundamentos da psicanálise de Freud a Lacan. v.1: as bases conceituais. Rio de Janeiro: Jorge Zahar, 2005.

LACAN, J. O Seminário, livro 5: As formações do inconsciente (1957/58). Rio de Janeiro: Jorge Zahar, 1999.

Escritos. Rio de Janeiro: Jorge Zahar, 1998.

O estádio do espelho como formador da função do eu (1949). In: Escritos. Rio de Janeiro: Zahar, 1998a.

. Subversão do sujeito e a dialética do desejo no inconsciente freudiano (1960). In: Escritos. Rio de Janeiro: Zahar, 1998b. 
Zahar, 1992.

O Seminário, livro 17: O Avesso da psicanálise. (1969/70) Rio de Janeiro: Jorge 1991.

O Seminário, livro 7: A Ética da psicanálise (1959/60). Rio de Janeiro: Jorge Zahar,

. O seminário, livro 11: Os quatro conceitos fundamentais da psicanálise (1964).

Rio de Janeiro: Jorge Zahar, 1985.

LASCH, C. A cultura do Narcisismo: A Vida americana numa era de esperança em declínio. Tradução Ernani Pavaneli, Rio de Janeiro: Imago, 1983.

MUUSS, R. Teorias da adolescência. Entrelivros, Belo Horizonte: 1976.

NOMINÉ, B. A adolescência ou A queda do anjo. Revista Marraio: da infância à adolescência. Rio de Janeiro: Rios Ambiciosos/ Formações clínicas do Campo Lacaniano, 2001.

POLLO, V. Mulheres histéricas. Rio de Janeiro: Contra capa. 2003.

ROUDINESCO, E. Análise e o arquivo. Rio de Janeiro: Jorge Zahar, 2006.

Eliana Julia Garritano é psicanalista pelo Instituto Brasileiro de Psicanálise Grupos e Instituições (IBRAPSI), mestre em Psicanálise, Saúde e Sociedade pela Universidade Veiga de Almeida (UVA), Psicóloga e Fonoaudióloga pela UVA.

E-mail: juliagarri@terra.com.br

Glória Sadala é doutora em comunicação pela UFRJ, Coordenadora do mestrado Psicanálise, saúde e sociedade, da Universidade Veiga de Almeida e Psicanalista de Formação Clínica do Campo Lacaniano. E-mail: gloriasadala@uva.br 